Original Article

\title{
Fever in Trauma Patients without Brain Injury
}

\author{
Boyoon Choi, Kiyoung Sung, Jinbeom Cho * \\ Department of Surgery, The Catholic University of Korea, College of Medicine, Seoul, Korea
}

\section{Article history:}

Received: March 1, 2020

Revised: June 3, 2020

Accepted: June 12, 2020

\section{${ }^{*}$ Corresponding Author:}

Jinbeom Cho

Department of Surgery, Bucheon St. Mary's

Hospital, The Catholic University of Korea

College of Medicine, 327, Sosa-ro, Bucheon,

Gyeonggi, Korea

E-mail: jinbum21@catholic.ac.kr

\section{ORCID}

Boyoon Choi

https://orcid.org/0000-0001-8479-0414

Kiyoung Sung

https://orcid.org/0000-0002-8369-425X

Jinbeom Cho

https://orcid.org/0000-0002-6329-016X

\section{ABSTRACT}

Purpose: Distinguishing a fever caused by infection from the necessary febrile response in injured patients is difficult, because trauma patients often have concomitant obvious infectious origins. In traumatic brain injury, early fever might be associated with worse clinical outcomes; however, few reports on trauma patients without brain injury are available.

Methods: In this retrospective observational study, consecutive trauma patients without brain injury who were admitted to the surgical intensive care unit during a 3 year period were included. The surgical and clinical outcomes were compared according to body temperature. Locally weighted scatterplot smoothing was used to identify the relationship between body temperature and injury severity.

Results: A total of 111 patients were included. Body temperature increased as the injury severity score increased up to 47.717, above which it decreased. Mortality was high in hypothermic patients (72.7\%; $p<0.001)$; however, few differences were observed between normothermic and hyperthermic patients ( $3.5 \%$ and $2.4 \%$, respectively). The nonsurvivors had lower body temperatures on the 1 st and 2 nd days after admission $\left(36^{\circ} \mathrm{C}\right.$ and $\left.36.9^{\circ} \mathrm{C}\right)$ compared with the survivors $\left(37.3^{\circ} \mathrm{C}\right.$ and $37.7^{\circ} \mathrm{C} ; p<0.001$ and $p=0.006$ ). In severely injured patients, low levels of inflammatory biomarkers and low body temperature were correlated with mortality.

Conclusions: Fever in trauma patients without brain injury is correlated with injury severity but not with prognosis. Hypothermia on the 1st and 2nd days after admission was significantly correlated with mortality. In severely injured patients, a decreased inflammatory response might play a certain role in promoting a high mortality rate.

Keywords: trauma; fever, traumatic brain injury, infection

\section{Introduction}

Fever is defined as a manifestation of cytokine release in response to a variety of stimuli [1-3]. Cytokines that induce febrile responses in the human body can be released by tissue trauma, bacterial endotoxins, or exotoxins. According to several articles on postoperative fever [4,5], the degree of the febrile response seems to be correlated with the intensity of the trauma. However, distinguishing a fever caused by infection from the necessary febrile response in injured patients remains difficult because trauma patients often have concomitant obvious infectious origins, such as intra-abdominal hollow viscus injury or perforation. In this study, we aimed to demonstrate and clarify the following hypotheses: (1) the fever in trauma patients might be correlated with injury severity; (2) the fever, which develops immediately after injury, might not have implications for the clinical outcomes; and (3) in severely injured patients, the absence of the early febrile response might indicate poor prognosis.

\section{Materials and Methods}

This was retrospective observational study. The medical records of trauma patients who were admitted to our surgical intensive care unit (ICU) and received final treatment in this 
hospital without transfer to other centers between January 2015 and December 2017 were collected and analyzed. The exclusion criteria were as follows: (1) patients with traumatic brain injury (TBI); (2) patients who were transferred from other hospitals to this hospital for further treatment; and (3) patients who received antipyretics within 4 days of admission to the ICU for the treatment of complications caused by fever because some patients received antipyretics during their body temperature was increasing. All injured patients were initially evaluated by our acute care surgical team in the emergency center, and underwent resuscitation, which included blood transfusion, crystalloid restriction, immediate diagnostic workup, and surgery as soon as possible. The injury severity score (ISS), based on the anatomical scoring system, hemodynamic parameters, laboratory variables, and body temperature (BT), was immediately recorded. The BT was checked regularly at patients' tympanic membranes at intervals of at least 2 hours, and the higher temperature was recorded if the measurements of both tympanic membranes revealed discordance. This protocol continued until the patients were transferred from the ICU to the general ward. We did not use antipyretics and did not perform any diagnostic work-up for the increased BT within 4 days of admission unless the patients exhibited serious physiologic stress or discomfort and metabolic demands of fever and shivering.

We classified the patients into three groups according to their maximal BT within 4 days of admission: (1) Group A, $\mathrm{BT}<37^{\circ} \mathrm{C}$; (2) Group B, $37^{\circ} \mathrm{C} \leq \mathrm{BT} \leq 38^{\circ} \mathrm{C}$; and (3) Group C, BT > $38^{\circ} \mathrm{C}$. We investigated and compared the following clinical and laboratory variables according to the patient groups: mortality, length of ICU stay, length of hospital stay, ISS, mechanical ventilation or not, vasopressor treatment or not, white blood cell (WBC) count, level of c-reactive protein (CRP), level of lactate, amount of red blood cell (RBC) transfusion, surgery or not, and intraperitoneal contamination or not. In addition, we analyzed the differences between surviving and deceased patients to identify any factors affecting mortality in the trauma patients. Finally, we selected subgroup patients who received vasopressor treatment to identify any correlation of BT with mortality in severely injured patients.

\section{Statistical analysis}

The normality assumption was not satisfied with the Kolmogorov-Smirnov test for most of the variables; therefore, nonparametric statistical methods were applied. The summary statistics are presented as numbers and percentages for categorical variables and as medians (interquartile range) for continuous variables. In the analysis of more than two groups, $p$ values were calculated using the Cochran-Armitage trend test for categorical variables and the Kruskal-Wallis test for continuous variables. In the analysis of two groups, the chi- square or Fisher's exact test was used to compare categorical variables, and the Wilcoxon rank sum test was used to compare continuous variables. We considered a two-sided $P<0.05$ to indicate statistical significance. We made a two-dimensional scatterplot in which variables included the ISS and BT of each patient and applied the locally weighted scatterplot smoothing (LOESS) method to graphically visualize the relationship between the BT and ISS. All statistical analyses were performed using the software package SAS 9.4 (SAS Institute, Inc., Cary, NC).

\section{Results}

A total of 111 patients were included in this study. Figure 1 illustrates the LOESS from the scatterplot of BT and ISS, which visualizes the correlation of BT with ISS in the entire cohort. The dotted line with black points represents the correlation of peak BT within 4 days of admission with ISS, and the solid line with empty points represents the correlation of peak BT on the day of admission with ISS. With this graph, we could grossly estimate that peak BT within 4 days of admission increased as the ISS increased to a certain point, above which it decreased. The turning point was calculated as an ISS of 47.717. Comparatively, the peak BT on the day of admission showed a relative tendency to decrease as the ISS increased.

The clinical and laboratory differences between the patient groups are described in Table 1: 11 patients were included in the group A; 58 in the group B; and 42 in the group C. ISS and initial lactate levels were significantly different between the patient groups ( $p<0.001$ and $p=0.003$, respectively): 1 ) the mean ISS was 66 in group A, 25 in group B, and 35.5 in group C;

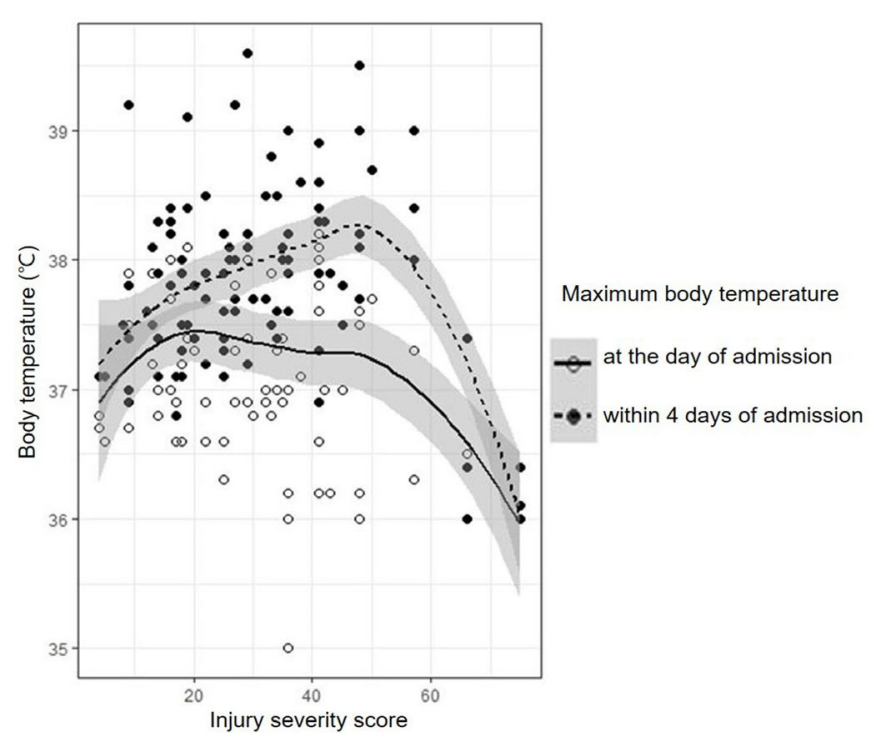

Figure 1 . The correlation of peak body temperature with injury severity score. 
2) the lactate levels were $7.7 \mathrm{mmol} / \mathrm{L}$ in group A, 3.0 in group $\mathrm{B}$, and 3.8 in group $\mathrm{C}$. The mortality was significantly higher in group A than in the other groups $(72.7 \% ; p<0.001)$; however, few differences were found between groups B and C (3.5\% and $2.4 \%$, respectively). Group $C$ patients were hospitalized for more days in both the ICU and general ward and exhibited higher levels of WBC and CRP than group A and B patients. On average, 16 units of RBC per patient were transfused in group A, 6.5 in group C, and 0 in group B $(p<0.001)$. Furthermore, no differences in the frequency of operation, intraperitoneal contamination, mechanical ventilation, and vasoactive drug infusion were observed between the groups.

Table 1. Demographics and clinical outcomes according to the body temperature.

\begin{tabular}{|c|c|c|c|c|c|}
\hline Variable & All patients $(N=111)$ & Group $\mathrm{A}(N=11)$ & Group B $(N=58)$ & Group C $(N=42)$ & $p$ \\
\hline Age (y) & $49(30,56)$ & $51(15,56)$ & $48(29,56)$ & $49.5(37,55)$ & 0.920 \\
\hline Sex & & & & & 0.010 \\
\hline Male & $85(76.6)$ & $5(45.5)$ & $44(75.9)$ & $36(85.7)$ & \\
\hline Female & $26(23.4)$ & $6(54.6)$ & $14(24.1)$ & $6(14.3)$ & \\
\hline Operation & & & & & 0.063 \\
\hline Yes & $64(57.7)$ & $7(63.6)$ & $26(44.8)$ & $31(73.8)$ & \\
\hline No & $47(42.3)$ & $4(36.4)$ & $32(55.2)$ & $11(26.2)$ & \\
\hline ISS (point) & $29(18,41)$ & $66(17,75)$ & $25(17,34)$ & $35.5(25,42)$ & $<0.001$ \\
\hline Intra peritoneal contamination & & & & & 0.871 \\
\hline Yes & $20(18)$ & $2(18.2)$ & $10(17.2)$ & $8(19.1)$ & \\
\hline No & $91(82)$ & $9(81.8)$ & $48(82.8)$ & $34(81)$ & \\
\hline \multicolumn{6}{|l|}{ Body temperature $\left({ }^{\circ} \mathrm{C}\right)$} \\
\hline 1st day & $37.3(36.8,37.8)$ & $36(36,36.6)$ & $37.2(36.8,37.5)$ & $37.9(37.3,38.2)$ & $<0.001$ \\
\hline 2nd day & $37.6(37.2,38.1)$ & $36.8(36,36.9)$ & $37.4(37.1,37.7)$ & $38.2(37.9,38.4)$ & $<0.001$ \\
\hline 3rd day & $37.5(37,37.9)$ & $36.5(36.4,36.6)$ & $37.3(37,37.5)$ & $38.1(37.8,38.4)$ & $<0.001$ \\
\hline 4th day & $37.3(36.9,37.7)$ & $36.3(36,36.6)$ & $37.1(36.9,37.4)$ & $37.8(37.4,38.2)$ & $<0.001$ \\
\hline Level of lactate $(\mathrm{mmol} / \mathrm{L})^{*}$ & $3.4(2.4,5.2)$ & $7.7(4.6,10.6)$ & $3(1.5,4.8)$ & $3.8(2.7,4.9)$ & 0.003 \\
\hline \multicolumn{6}{|l|}{ WBC count $(/ \mathrm{mL})$} \\
\hline 1st day & $11,980(8,590,14,960)$ & $8,050(6,810,14,620)$ & $12.245(8,700,15,070)$ & $11,125(8,570,14,930)$ & 0.268 \\
\hline 2nd day & $9,490(7,570,11,630)$ & $7,140(4,030,8,270)$ & $9.900(8,320,12,050)$ & $9,360(7 ., 470,11,410)$ & 0.017 \\
\hline 3rd day & $8,580(6,710,11,250)$ & $5,575(4,730,7,350)$ & $8.990(7,020,11,910)$ & $8,405(6,870,11,210)$ & 0.037 \\
\hline 4th day & $8,310(6,410,10,960)$ & $5,400(4,690,5,640)$ & $8.185(6,550,10,780)$ & $8,590(6,080,11,300)$ & 0.031 \\
\hline \multicolumn{6}{|l|}{ Level of CRP (mg/L) } \\
\hline 1st day & $0.8(0.3,2.5)$ & $0.5(0.3,1)$ & $1.6(0.2,1.7)$ & $1.2(0.5,7.9)$ & 0.030 \\
\hline 2nd day & $34(9.6,82.9)$ & $6.8(3.8,7.9)$ & $22.5(5.8,61)$ & $73.3(18.8,102.3)$ & $<0.001$ \\
\hline 3rd day & $91.7(32.7,156.1)$ & $36.9(17.4,60.4)$ & $74.7(17.9,140.7)$ & $127.7(80.6,184.3)$ & 0.006 \\
\hline 4th day & $88.6(46.8,157.1)$ & $23.8(9.7,60.5)$ & $78.2(26.4,122)$ & $112.4(65.9,171.7)$ & 0.013 \\
\hline Hospital course & & & & & $<0.001$ \\
\hline Survived to discharge & $100(90.1)$ & $3(27.3)$ & $56(96.6)$ & $41(97.6)$ & \\
\hline Mortality during ICU stay & $11(9.9)$ & $8(72.7)$ & $2(3.5)$ & $1(2.4)$ & \\
\hline Mechanical ventilation & & & & & 0.756 \\
\hline Yes & $32(28.8)$ & $8(72.7)$ & $8(13.8)$ & $26(61.9)$ & \\
\hline No & $79(71.2)$ & $3(27.3)$ & $50(86.2)$ & $16(38.1)$ & \\
\hline
\end{tabular}


Table 1. (Continued).

\begin{tabular}{|c|c|c|c|c|c|}
\hline Variable & All patients $(N=111)$ & Group $\mathrm{A}(N=11)$ & Group B $(N=58)$ & Group C $(N=42)$ & $p$ \\
\hline Vasopressors or inotropics & & & & & 0.289 \\
\hline Yes & $29(26.1)$ & $8(72.7)$ & $8(13.8)$ & $29(69.1)$ & \\
\hline No & $82(73.9)$ & $3(27.3)$ & $50(86.2)$ & $13(31)$ & \\
\hline Length of ICU stay & $4(3,5)$ & $2(1,4)$ & $3(2,5)$ & $5(3,10)$ & $<0.001$ \\
\hline Length of hospital stay & $12(9,20)$ & $4(1,9)$ & $11(8,18)$ & $17(11,27)$ & $<0.001$ \\
\hline RBC transfusion & $2(0,9)$ & $16(2,47)$ & $0(0,2)$ & $6.5(3,10)$ & $<0.001$ \\
\hline
\end{tabular}

Data are presented as $n$ (\%) for categorical variables, and median (IQR) for continuous variables.

$p$ values are calculated using Cochran-Armitage trend test for categorical variables and Kruskal-Wallis test for continuous variables.

*at the time of admission.

ISS = injury severity score; $\mathrm{WBC}=$ white blood cell; $\mathrm{CRP}=\mathrm{c}$-reactive protein; $\mathrm{ICU}=$ intensive care unit; $\mathrm{RBC}=$ red blood cell.

Table 2 demonstrates the differences between surviving and deceased patients. The deceased patients had significantly lower BT on the $1^{\text {st }}$ and $2^{\text {nd }}$ days after admission $\left(36^{\circ} \mathrm{C}\right.$ and $\left.36.9^{\circ} \mathrm{C}\right)$ than the surviving patients $\left(37.3^{\circ} \mathrm{C}\right.$ and $37.7^{\circ} \mathrm{C} ; p<0.001$ and $p=0.006)$. In addition, the ISS, initial lactate level, and incidence of ventilator and vasoactive drug treatment were higher in the deceased group than in the surviving group. The deceased patients received more RBC transfusions than the surviving patients, and the survivors were hospitalized for more days than the nonsurvivors. In the analysis of severely injured patients who received vasopressors or inotropic treatment (Table 3 ), a high ISS point, low WBC count on the $4^{\text {th }}$ day after admission, low level of CRP on the $2^{\text {nd }}, 3^{\text {rd }}$, and $4^{\text {th }}$ days after admission, large amount of transfused RBCs, and low BT on the 1 st to $4^{\text {th }}$ days after admission were significantly correlated with mortality. The hospital and ICU length of stay were longer in the surviving patients than in the deceased patients.

Table 2. Comparison by the hospital course.

\begin{tabular}{|c|c|c|c|}
\hline Variable & Survived to discharge $(N=100)$ & ICU mortality $(N=11)$ & $p$ \\
\hline Age $(y)$ & $49(29.5,55.5)$ & $53(44,56)$ & 0.433 \\
\hline Sex & & & 0.125 \\
\hline Male & $79(79)$ & $6(54.6)$ & \\
\hline Female & $21(21)$ & $5(45.5)$ & \\
\hline Operation & & & 0.114 \\
\hline Yes & $55(55)$ & $9(81.8)$ & \\
\hline No & $45(45)$ & $2(18.2)$ & \\
\hline ISS (point) & $26(17.5,36)$ & $66(45,75)$ & $<0.001$ \\
\hline Intra peritoneal contamination & & & 1.000 \\
\hline Yes & $18(18)$ & $2(18.2)$ & \\
\hline No & $82(82)$ & $9(81.8)$ & \\
\hline \multicolumn{4}{|l|}{ Body temperature $\left({ }^{\circ} \mathrm{C}\right)$} \\
\hline 1st day & $37.3(36.9,37.9)$ & $36(36,36.5)$ & $<0.001$ \\
\hline 2nd day & $37.7(37.3,38.1)$ & $36.9(36,37.4)$ & 0.006 \\
\hline 3rd day & $37.5(37.1,38)$ & $36.8(36.4,37.5)$ & 0.105 \\
\hline 4th day & $37.3(37,37.7)$ & $36(36,37.4)$ & 0.080 \\
\hline
\end{tabular}


Table 2. (Continued).

\begin{tabular}{|c|c|c|c|}
\hline Variable & Survived to discharge $(N=100)$ & ICU mortality $(N=11)$ & $p$ \\
\hline Level of lactate $(\mathrm{mmol} / \mathrm{L})^{*}$ & $3.4(2.2,4.8)$ & $6.2(3.3,9.1)$ & 0.012 \\
\hline \multicolumn{4}{|l|}{ WBC count $(/ \mathrm{mL})$} \\
\hline 1st day & $11.865(8.665,15.015)$ & $12.330(6.810,14.930)$ & 0.474 \\
\hline 2nd day & $9.585(7.785,11.580)$ & $7.140(4.030,13.010)$ & 0.142 \\
\hline 3rd day & $8.580(6.710,11.240)$ & $10.230(5.500,19.960)$ & 0.761 \\
\hline 4th day & $8.400(6.450,10.960)$ & $5.095(3.645,12.735)$ & 0.147 \\
\hline \multicolumn{4}{|l|}{ Level of CRP (mg/L) } \\
\hline 1st day & $0.8(0.4,2.5)$ & $0.5(0.3,3.8)$ & 0.634 \\
\hline 2nd day & $34.4(10.11,88)$ & $6.8(5.5,71.6)$ & 0.326 \\
\hline 3rd day & $92.7(27.6,163.1)$ & $83.5(60.4,92.5)$ & 0.910 \\
\hline 4th day & $93.3(46.8,157.1)$ & $62.6(42.1,190.4)$ & 0.840 \\
\hline Mechanical ventilation & & & $<0.001$ \\
\hline Yes & $21(21)$ & $11(100)$ & \\
\hline No & $79(79)$ & $0(0)$ & \\
\hline Vasopressors or inotropics & & & $<0.001$ \\
\hline Yes & $19(19)$ & $10(90.9)$ & \\
\hline No & $81(81)$ & $1(9.1)$ & \\
\hline Length of ICU stay (d) & $4(3,6)$ & $3(1,4)$ & 0.025 \\
\hline Length of hospital stay (d) & $13(10,23)$ & $3(1,4)$ & $<0.001$ \\
\hline RBC transfusion (units) & $1.5(0,6.5)$ & $20(12,47)$ & $<0.001$ \\
\hline
\end{tabular}

Data are presented as $n$ (\%) for categorical variables and median (IQR) for continuous variables.

$p$ values are calculated using chi-square test or Fisher's exact test for categorical variables and Wilcoxon rank sum test for continuous variables. *at the time of admission.

ICU = intensive care unit; ISS = injury severity score; $\mathrm{WBC}=$ white blood cell; $\mathrm{CRP}=\mathrm{c}$-reactive protein; $\mathrm{RBC}=$ red blood cell.

Table 3. Comparison by the hospital course in patients received vasopressors or inotropics treatment.

\begin{tabular}{|c|c|c|c|}
\hline Variable & Survived to discharge $(N=19)$ & ICU mortality $(N=10)$ & $p$ \\
\hline Age (y) & $53(42,63)$ & $52(44,55)$ & 0.550 \\
\hline Sex & & & 0.011 \\
\hline Male & $18(94.7)$ & $5(50)$ & \\
\hline Female & $1(5.3)$ & $5(50)$ & \\
\hline Operation & & & 1.000 \\
\hline Yes & $16(84.2)$ & $8(80)$ & \\
\hline No & $3(15.8)$ & $2(20)$ & \\
\hline ISS (point) & $41(32,57)$ & $70.5(66,75)$ & $<0.001$ \\
\hline Intra peritoneal contamination & & & 0.367 \\
\hline Yes & $6(31.6)$ & $1(10)$ & \\
\hline No & $13(68.4)$ & $9(90)$ & \\
\hline
\end{tabular}


Table 3. (Continued).

\begin{tabular}{|c|c|c|c|}
\hline Variable & Survived to discharge $(N=19)$ & ICU mortality $(N=10)$ & $p$ \\
\hline \multicolumn{4}{|l|}{ Body temperature $\left({ }^{\circ} \mathrm{C}\right)$} \\
\hline 1st day & $37.3(36.3,38)$ & $36(36,36.2)$ & $<0.001$ \\
\hline 2nd day & $38(37.5,38.4)$ & $36.5(36,37)$ & 0.001 \\
\hline 3rd day & $38.1(37.8,38.4)$ & $36.4(36.4,37.2)$ & 0.003 \\
\hline 4th day & $37.9(37.3,38.3)$ & $36(36,36)$ & 0.007 \\
\hline Level of lactate $(\mathrm{mmol} / \mathrm{L})^{*}$ & $5.2(4.1,6.7)$ & $6.4(5,9.1)$ & 0.210 \\
\hline \multicolumn{4}{|l|}{ WBC count $(/ \mathrm{mL})$} \\
\hline 1st day & $8,930(7,750,12,980)$ & $10,140(6,810,13,660)$ & 0.872 \\
\hline 2nd day & $9,200(7 ., 470,11,180)$ & $6,090(4,030,7,500)$ & 0.135 \\
\hline 3rd day & $8,370(6,870,9,980)$ & $7,350(5,500,19,960)$ & 0.831 \\
\hline 4th day & $8,710(6,750,10,930)$ & $4,690(2,600,5,500)$ & 0.010 \\
\hline \multicolumn{4}{|l|}{ Level of CRP (mg/L) } \\
\hline 1st day & $1.2(0.4,2.5)$ & $0.5(0.3,1)$ & 0.094 \\
\hline 2nd day & $102.3(52.5,151.7)$ & $6.8(5.5,6.9)$ & 0.015 \\
\hline 3rd day & $186.2(134.2,245.5)$ & $72(48.6,88)$ & 0.005 \\
\hline 4th day & $151.8(107.5,188.9)$ & $60.5(23.8,64.6)$ & 0.022 \\
\hline Mechanical ventilation & & & 0.068 \\
\hline Yes & $13(68.4)$ & $10(100)$ & \\
\hline No & $6(31.6)$ & $0(0)$ & \\
\hline Length of ICU stay (d) & $9(5,16)$ & $2.5(1,4)$ & $<0.001$ \\
\hline Length of hospital stay (d) & $27(20,41)$ & $2.5(1,4)$ & $<0.001$ \\
\hline RBC transfusion (units) & $10(6,15)$ & $25(16,47)$ & 0.002 \\
\hline
\end{tabular}

Data are presented as $n(\%)$ for categorical variables and median (IQR) for continuous variables.

$p$ values are calculated using Fisher's exact test for categorical variables and Wilcoxon rank sum test for continuous variables.

*At the time of admission.

ICU = intensive care unit; ISS = injury severity score; $\mathrm{WBC}$ = white blood cell; $\mathrm{CRP}$ = c-reactive protein; $\mathrm{RBC}=$ red blood cell.

\section{Discussion}

The results of this study strongly supported our hypotheses that early fever in trauma patients without brain injury is correlated with injury severity but not with prognosis. Rather, hypothermia on the $1^{\text {st }}$ and $2^{\text {nd }}$ days after admission was significantly correlated with mortality, and the hypothermic patient group had a higher mortality rate than the other patients. In severely injured patients, we carefully suggest that the decreased inflammatory response might play a certain role in promoting a high mortality rate, as we could observe that hypothermia on the $1^{\text {st }}$ to $4^{\text {th }}$ days following admission, along with a low level of inflammatory biomarkers, such as CRP and WBC, were correlated with mortality in the subgroup analysis of patients who received vasoactive drug treatment.

The methodology of this study is acceptable, though it is different from that in previous works. First, we noticed that the previous studies mainly included only TBI patients or all trauma patients, including TBI. In our study, therefore, we excluded TBI patients to reduce the confounding bias, as the fever in TBI might be caused by a change in the thermoregulatory hypothalamic set point due to direct neuronal damage [6]. Early fever after TBI has been regarded as the secondary insult to brain structures [7], and a recent large prospective study revealed that fever might be associated with worse clinical outcomes and mortality in TBI [8], though the results seem to be conflicting [9]. However, we empirically speculated from our clinical experiences that early fever did not worsen clinical outcomes in non-TBI patients; therefore, we set a hypothesis contrary to the established data acquired from TBI patients. The patients included in this study could represent non-TBI and major trauma patients because only patients who required surgical ICU admission were included. 
In addition, we investigated BT within 4 days of ICU admission because new or persistent fever $>4$ days after surgery might indicate a persistent infectious source or new complications, though fever may last $\geq 72$ hours postoperatively even in patients who received definite surgical source control and timely antibiotic treatment [10]. Since the BT varies according to gender, age, measurement methods, site, and time, defining normal BT is difficult [11]. In our study, we applied the recommendations of the American College of Critical Care Medicine guidelines published in 2008 [10]: 1) fever is defined as a temperature elevation $>38^{\circ} \mathrm{C}$ for $>1$ hour; 2 ) normal BT is generally considered to be $37^{\circ} \mathrm{C}$; and 3 ) tympanic membrane BT via infrared ear thermometry is an acceptable method of measuring core BT. Finally, we used LOESS to demonstrate any correlations of BT with ISS because the two-dimensional plots of BT and ISS showed no specific order, as shown in Figure 1. LOESS is a nonparametric regression that uses local weighted regression, and a smoothing parameter is calculated as a third variable in addition to the two established variables. The predictor in nonparametric regression analysis does not take a predetermined form but is constructed according to information derived from the data. While LOESS requires large, densely sampled data sets and cannot produce a regression function that is easily represented by a mathematical formula, it can be used as a simple strategy for fitting smooth curves to empirical data [12].

Fever can be a hallmark of systemic infection or surgical complications, and generating a fever is a metabolically costly process, requiring an $11-13 \%$ increase in oxygen consumption to elevate $1^{\circ} \mathrm{C}$ in body temperature [13]. Therefore, surgeons tend to be nervous when their patients become febrile and try to find any possible infectious source. Comparatively, in 1942, Cuthbertson first described that the metabolic responses after an injury could be classified into two phases: the ebb and flow phases [14]. In this model, fever is a physiologic reaction of the increased metabolic rate in the flow phase, which is a period of convalescence; therefore, fever can be accepted as an essential and common event after injury. The pathophysiologic implication of fever remains unclear. In critically ill patients, fever $\geq 39.5^{\circ} \mathrm{C}$ was associated with increased mortality [15]. In contrast, fever can be an adaptive response to infection, and elevated peak BT in ICU patients with infections was correlated with decreased mortality [16]. In our study, we considered mechanical ventilation and intraperitoneal contamination as the possible infectious causes of early fever in surgical ICU patients with trauma; however, the results revealed no differences between patient groups, suggesting that the early fever in trauma might not be caused by infection. Catheterrelated infection and surgical site infection were not included because of their late-onset characteristics. The mortality, ISS, and lactate levels were higher in group A than in groups
$B$ and $C$, and these variables were higher in group $C$ than in group B. These findings were consistent with Figure 1, which illustrates that peak BT within 4 days of admission increased as the ISS increased to a certain point, above which it decreased. In severely injured patients, the peak BT of the survivors was $37.3^{\circ} \mathrm{C}$ on the $1^{\text {st }}$ day, $38^{\circ} \mathrm{C}$ on the $2^{\text {nd }}$ day, $38.1^{\circ} \mathrm{C}$ on the $3^{\text {rd }}$ day, and $37.9^{\circ} \mathrm{C}$ on the $4^{\text {th }}$ day, which can be considered as fever.

First, since few cases resulted in mortality $(N=10)$, we could not perform multivariate analysis to demonstrate the correlation of BT with mortality. Second, this study was a retrospective observational study; therefore, a microbial culture test and other inflammatory biomarkers, such as procalcitonin, were not included, which would be helpful in identifying the relationship between BT and established infection. Third, the decreasing BT in severely injured patients might be for the high injury severity or for the aggressive resuscitation. However, it was difficult to exclude the effect of resuscitation because the amount of resuscitation tends to be always increased as ISS increase. It was also difficult to analyze the initial BT because the records often were discordant for the issue of heterogeneity in environment, transport system, and prehospital management. Finally, LOESS could not generate a scientific formula that can definitely explain the correlation of BT with ISS, showing only an approximate relationship. However, the studies that report the clinical implication of fever in non-TBI trauma patients are rare, and we expect that this study would be helpful in promoting further well-designed prospective randomized trials.

\section{Conclusion}

Early fever after injury was correlated with ISS but not with prognosis. In severely injured patients, the absence of the febrile response might indicate poor prognosis. Surgeons may wait and see what happens without unnecessary intervention when they encounter unpredicted febrile responses during the early period of trauma management, though the injured patients often have concomitant obvious infectious origins, such as peritonitis. Rather, hypothermia might be a surrogate for profound injury, and surgeons should prepare for clinical deterioration.

\section{Conflicts of Interest}

No potential conflict of interest relevant to this article was reported. 


\section{Ethical Statement}

This study was approved by the institutional review board of Bucheon St. Mary's Hospital, College of Medicine, The Catholic University of Korea, Korea (HC19RESI0006). The statistical methods of this study were reviewed by the Clinical Research Coordinating Center, Institute of Biomedical Industry, The Catholic University of Korea (no.: 1803-1351-01). The abstract was presented orally at the Annual congress of Korean surgical society, held on Nov 1-3, 2018, in Seoul, Korea.

\section{References}

[1] Netea MG, Kullberg BJ, Van der Meer JW. Circulating cytokines as mediators of fever. Clin Infect Dis 2000;31 Suppl 5:S178-84.

[2] Blatteis CM, Sehic E, Li S. Pyrogen sensing and signaling: old views and new concepts. Clin Infect Dis 2000;31 Suppl 5:S168-77.

[3] Saper CB, Breder CD. The neurologic basis of fever. N Engl J Med 1994;330(26):1880-6.

[4] Dauleh MI, Rahman S, Townell NH. Open versus laparoscopic cholecystectomy: a comparison of postoperative temperature. J R Coll Surg Edinb 1995;40(2):116-8.

[5] Clark JA, Bar-Yosef S, Anderson A, Newman MF, Landolfo K, Grocott HP. Postoperative hyperthermia following off-pump versus on-pump coronary artery bypass surgery. J Cardiothorac Vasc Anesth 2005;19(4):426-9.
[6] Bao L, Chen D, Ding L, Ling W, Xu F. Fever burden is an independent predictor for prognosis of traumatic brain injury. PLoS One 2014;9(3):e90956.

[7] Li J, Jiang JY. Chinese Head Trauma Data Bank: effect of hyperthermia on the outcome of acute head trauma patients. J Neurotrauma 2012;29(1):96-100.

[8] Hinson HE, Rowell S, Morris C, Lin AL, Schreiber MA. Early fever after trauma: Does it matter? J Trauma Acute Care Surg 2018;84(1):19-24.

[9] Bengualid V, Talari G, Rubin D, Albaeni A, Ciubotaru RL, Berger J. Fever in trauma patients: evaluation of risk factors, including traumatic brain injury. Am J Crit Care 2015;24(2):e1-5.

[10] O'Grady NP, Barie PS, Bartlett JG, Bleck T, Carroll K, Kalil AC, et al. Guidelines for evaluation of new fever in critically ill adult patients: 2008 update from the American College of Critical Care Medicine and the Infectious Diseases Society of America. Crit Care Med 2008;36(4):133049.

[11] Sund-Levander M, Forsberg C, Wahren LK. Normal oral, rectal, tympanic and axillary body temperature in adult men and women: a systematic literature review. Scand J Caring Sci 2002;16(2):122-8.

[12] Jacoby WG. Loess: a nonparametric, graphical tool for depicting relationships between variables. Elect Stud 2000;19(4):577-613.

[13] Cannon JG. Perspective on fever: the basic science and conventional medicine. Complement Ther Med 2013;21 Suppl 1:S54-60.

[14] Mizushima Y, Ueno M, Idoguchi K, Ishikawa K, Matsuoka T. Fever in trauma patients: friend or foe? J Trauma 2009;67(5):1062-5.

[15] Laupland KB, Shahpori R, Kirkpatrick AW, Ross T, Gregson DB, Stelfox HT. Occurrence and outcome of fever in critically ill adults. Crit Care Med 2008;36(5):1531-5.

[16] Young PJ, Saxena M, Beasley R, Bellomo R, Bailey M, Pilcher D, et al. Early peak temperature and mortality in critically ill patients with or without infection. Intensive Care Med 2012;38:437-44. 